\title{
AVALIAÇÃO DA QUALIDADE DE PESCADA AMARELA (Cynoscion acoupa) COMERCIALIZADA RESFRIADA UTILIZANDO O MÉTODO DO ÍNDICE DE QUALIDADE (MIQ), ANÁLISES QUÍMICAS E MICROBIOLÓGICAS
}

\begin{abstract}
Analisou-se a qualidade química e microbiológica da pescada amarela (Cynoscion acoupa), proveniente de 14 pontos de comercialização das cidades de Santos, São Vicente e Praia Grande, (litoral do Estado de São Paulo), e utilizou-se o Método do Índice de Qualidade (MIQ) para avaliação sensorial do seu frescor. Amostras de pescada amarela obtidas de pescador artesanal no mesmo dia da captura também foram analisadas. As amostras de pescada amarela obtidas no comércio apresentaram Índices de Qualidade (IQ) variando de 2 a 23, indicando tempo provável após captura de 3 até 14 dias, respectivamente. Todos os peixes analisados estavam livres de Salmonella sp. e Escherichia coli, e as contagens de Staphylococcus aureus enquadraram-se nos limites estabelecidos pela legislação brasileira. Contagens de psicrotróficos acima de 7 Log UFC/g foram observadas em $50 \%$ dos peixes. Coliformes totais variaram de $2 \mathrm{Log}$ UFC/g até $7 \mathrm{Log}$ UFC/g. Os valores de trimetilamina e bases nitrogenadas voláteis encontrados foram maiores que os estipulados pela legislação brasileira em $50 \%$ e $65 \%$ dos peixes, respectivamente. Tais resultados alertam sobre o baixo grau de frescor em que normalmente essa espécie de peixe é oferecida no varejo e apontam para a necessidade de educar comerciantes e manipuladores sobre as condições adequadas de manuseio e armazenamento de peixes in natura a fim de preservar ao máximo sua qualidade.
\end{abstract}

PALAVRAS-CHAVE: FRESCOR; PEIXE; MIQ; AVALIAÇÃO SENSORIAL.

* Mestre em Ciência e Tecnologia de Alimentos, Faculdade de Zootecnia e Engenharia de Alimentos, Universidade de São Paulo (USP), Pirassununga, SP (e-mail: anapaulabillar@usp.br).

** Doutora em Ciência de Alimentos, Departamento de Engenharia de Alimentos, Faculdade de Zootecnia e Engenharia de Alimentos, USP, Pirassununga, SP (e-mail: martakushida@usp.br).

*** Doutora em Tecnologia de Alimentos, Departamento de Engenharia de Alimentos, Faculdade de Zootecnia e Engenharia de Alimentos, USP, Pirassununga, SP (e-mail: julagui@usp.br). 


\section{INTRODUÇÃo}

A procura por hábitos saudáveis, o aumento da renda da população e a valorização da moeda, aliados a ações públicas contribuíram para elevar o consumo de pescado no Brasil (BRASIL, 2010). Resultados do estudo realizado pelo Ministério da Pesca e Aquicultura (MPA) revelaram que o consumo per capita aparente de pescado em 2010 foi de $9,75 \mathrm{~kg} /$ habitante/ano, crescendo $8 \%$ em relação ao ano de 2009 (BRASIL, 2012a) e aproximando-se muito do patamar considerado ideal pela Organização Mundial de Saúde de $12 \mathrm{~kg} /$ habitante/ano (BRASIL, 2010).

Embora sejam conhecidos os benefícios proporcionados pelo consumo de pescado, esse alimento também pode ser fonte de compostos prejudiciais à saúde. Por ser altamente perecível, o frescor representa a característica determinante da qualidade do peixe como alimento, tanto para aqueles consumidos crus ou usados na culinária doméstica, quanto para aqueles que serão processados (MAZORRA-MANZANO et al., 2000).

A avaliação do frescor do pescado pode ser realizada por meio de análises microbiológicas, físico-químicas e sensoriais. Em relação à inocuidade de pescado in natura resfriado não consumido cru, a Agência Nacional de Vigilância Sanitária (ANVISA) estabelece (RDC 12, de 2 de janeiro

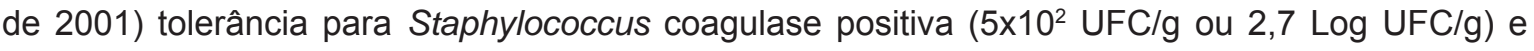
Salmonella sp. (ausência em 25 g) (BRASIL, 2001). Não há limite para Coliformes em pescado in natura resfriado não consumido cru, sendo utilizado o limite estipulado para outros produtos derivados de pescado. Os métodos químicos normalmente aplicados baseiam-se na quantificação de bases nitrogenadas voláteis (BNV) e trimetilamina (TMA), cujos limites são $30 \mathrm{mg}$ e $4 \mathrm{mg}$ de nitrogênio/100 g (BRASIL, 1997). O teor de triptofano livre tem se mostrado bom índice para avaliação do frescor em invertebrados marinhos (LAPA-GUIMARÃES, FELÍCIO e CONTRERAS, 2013; LAPA-GUIMARÃES, FELÍCIO e CONTRERAS, 2005; ROMO et al., 1996) e merluza (Merluccius merluccius) (RUIZ-CAPILLAS e MORAL, 2001), pois sua concentração aumenta progressivamente nesses tipos de pescado durante o armazenamento refrigerado. Tratando-se de metodologia relativamente simples seria interessante verificar sua utilidade para outras espécies de peixes.

A análise sensorial tem sido a principal forma de avaliação da qualidade do pescado no setor pesqueiro e serviços de inspeção (SVEINSDÓTTIR et al., 2002), destacando-se o Método do Índice de Qualidade (MIQ), desenvolvido originalmente pela Tasmanian Food Research Unit (BREMNER, 1985). O método (espécie-específico) tem por objetivo obter correlação linear entre a qualidade sensorial (expressa pela soma de pontos de demérito) e o tempo de armazenamento em gelo, tornando possível estimar o tempo decorrido desde a captura do pescado e prever o restante de sua vida útil (HYDILG e NIELSEN, 1997). De acordo com Vaz-Pires e Seixas (2006), o protocolo MIQ deve se tornar o principal método a ser utilizado para inspeção mais precisa e decisões claras sobre a qualidade sensorial do pescado. No Brasil, o protocolo MIQ foi desenvolvido para algumas espécies, tais como pescada amarela (Cynoscion acoupa) (SANTOS et al., 2014; SANTOS, 2011), corvina (Micropogonias furnieri) (TEIXEIRA et al., 2009), camarão (Litopenaeus vannamei) (OLIVEIRA 2005), tilápia (Oreochromis niloticus) (RODRIGUES, 2008) e sardinha (Sardinella brasiliensis) (ANDRADE et al., 2012).

A pescada amarela (Cynoscion acoupa) foi a quarta espécie de peixe mais capturada no litoral brasileiro em 2011 (21.074,2 t) (BRASIL, 2012b) e em 2010, aproximadamente, $32.000 \mathrm{~kg}$ da espécie foram capturados no litoral de São Paulo (SÃO PAULO, 2011). A comercialização da pescada amarela in natura no litoral do estado de São Paulo ocorre em diversos tipos de estabelecimentos comerciais, e em muitos deles observam-se condições precárias de armazenamento, exposição e manipulação, sujeitando os consumidores a adquirir peixes inadequados para consumo.

O objetivo deste estudo foi avaliar a qualidade de pescada amarela comercializada resfriada em Santos, São Vicente e Praia Grande por meio de análises químicas, microbiológicas e avaliação sensorial utilizando-se o protocolo MIQ. 


\section{MATERIAL E MÉTODOS}

\subsection{AQUISIÇÃO DAS MATÉRIAS-PRIMAS, ARMAZENAMENTO E AMOSTRAGEM}

Amostras de pescada amarela $(n=39)$ foram adquiridas em 14 pontos de comercialização de três cidades do litoral de São Paulo (Santos, São Vicente e Praia Grande) durante os meses de outubro, novembro e dezembro de 2010 e fevereiro de 2011. Os seis pontos de comercialização em Santos foram denominados de A, B, C, D, E e F, correspondendo os três primeiros a vendedores ambulantes e os outros a peixarias. Em Praia Grande foram cinco pontos de comercialização denominados G, H, I, J e K, e em São Vicente três pontos de comercialização denominados L, M e $\mathrm{N}$, sendo todos peixarias. Cada amostra foi composta por 3 peixes (exceto para $\mathrm{A}, \mathrm{B}$ e $\mathrm{C}$, pois no momento da aquisição apenas 2 peixes estavam disponíveis). Os peixes, parcialmente eviscerados no local de aquisição, permaneceram com as guelras, membrana peritoneal e rim intactos, retirandose apenas o conteúdo da cavidade abdominal. Os peixes não foram lavados após a evisceração. As amostras, embaladas em sacos plásticos e acondicionadas em caixa isotérmica com gelo potável, foram transportadas no mesmo dia ao laboratório da Faculdade de Zootecnia e Engenharia de Alimentos (FZEA), em Pirassununga. Os peixes destinados à avaliação sensorial não foram submetidos às análises microbiológicas e químicas devido sua manipulação pelos avaliadores, além da necessidade de deixar os peixes disponíveis por tempo variável até o final da análise sensorial.

Amostras de pescada amarela $(n=7)$ adquiridas no dia da captura e um dia após a captura, diretamente de pescador artesanal, nos meses de maio e outubro de 2010 foram avaliadas para as mesmas características de qualidade das amostras procedentes do comércio. Acompanhou-se a obtenção desses peixes desde a colocação da rede até o desembarque, havendo conhecimento assegurado do tempo após captura.

\subsection{AVALIAÇÃO SENSORIAL}

As sete pessoas que formaram a equipe de avaliadores possuem conhecimento sobre a aplicação do método do índice de qualidade e avaliação sensorial de frescor de pescado. As amostras de pescada amarela foram dispostas sobre camada de gelo em caixas isotérmicas. Durante a análise, o julgador recebeu o protocolo MIQ desenvolvido por Santos (2011) para avaliação das características sensoriais encontradas de acordo com a observação individual. Segundo esse protocolo são avaliados 14 atributos da pescada amarela relacionados ao aspecto geral e às características dos olhos, brânquias, abdome, rim e musculatura, podendo somar até 23 pontos de demérito durante o armazenamento em gelo. Mediante avaliações efetuadas durante o armazenamento em gelo de dois lotes de pescada amarela parcialmente eviscerada obteve-se a curva de calibração apresentada na Equação 1, relacionando o tempo desde a captura e a qualidade sensorial (SANTOS, 2011). Utilizou-se essa curva de calibração para estimar os tempos de captura das amostras de pescada amarela adquiridas nos pontos de comercialização.

$$
\text { Equação } 1 \quad I Q=1,3451 d-0,4706 \text { em que } d=\text { dias após captura }
$$

\subsection{AVALIAÇÃO MICROBIOLÓGICA}

Cortou-se um filé de cada peixe em pedaços pequenos (menores que $1 \mathrm{~cm}^{3}$ ), os quais foram transferidos para béqueres estéreis identificados. Em fluxo laminar, amostras de $25 \mathrm{~g}$ de pedaços de filé de cada peixe foram pesadas dentro de sacos estéreis de $500 \mathrm{~mL}$ identificados, adicionando-se $225 \mathrm{~mL}$ de Água Peptonada Tamponada (APT) (Oxoid) 0,1 \%. Os sacos com as amostras foram fechados e submetidos à agitação em homogeneizador da marca Marconi por 3 minutos, originando a diluição $10^{-1}$ de cada amostra. Obtiveram-se as diluições $10^{-2}, 10^{-3}, 10^{-4}, 10^{-5} \mathrm{e}$ 
$10^{-6}$, mediante diluições sequenciais com APT.

Para a determinação de micro-organismos psicrotróficos seguiu-se o método descrito por Johnston e Tompkin (1992). Adicionaram-se alíquotas de 0,1 $\mathrm{mL}$ das diluições em placas de Petri contendo Ágar Padrão para Contagem (PCA) (Oxoid). As placas foram invertidas e incubadas a $20{ }^{\circ} \mathrm{C}$ por 3 dias, efetuando-se a contagem de colônias isoladas com contador de colônias. Para a determinação de Staphylococcus coagulase positiva empregou-se o método oficial n. 2003.11 da AOAC (2007). Alíquotas de $1 \mathrm{~mL}$ das diluições preparadas de acordo com a estimativa de presença de S. aureus foram inoculadas no centro de placas Petrifilm ${ }^{\mathrm{TM}} 3 \mathrm{M}$. Após incubação por $24 \mathrm{~h}$ a $37^{\circ} \mathrm{C}$, as colônias típicas foram quantificadas de acordo com as recomendações do fabricante. Para a determinação de Salmonella utilizou-se o BAX® System PCR Assay for Salmonella, fabricado pela Du Pont Qualicon. Tal metodologia, validada por Kushida (2005), foi aprovada pelo MAPA e certificada pelo AOAC Research Institute sob $n^{\circ} 100.201$ (AOAC, 2007). Para a contagem de bactérias do grupo coliformes foram utilizadas placas do kit Compact Dry EC (Nissui Pharmaceutical Company LTD), inoculando-se alíquotas de $1 \mathrm{~mL}$ das diluições no centro das placas. Após o período de incubação de $24 \mathrm{~h}$ a $37^{\circ} \mathrm{C}$, os resultados foram interpretados de acordo com as orientações do fabricante: colônia vermelha/cor-de-rosa indica presença de coliformes, exceto Escherichia coli, enquanto colônias azul/violeta indicam a presença de E. coli. A soma das colônias vermelhas e azuis representa o número total do grupo coliformes (NISSUI..., 2009).

\subsection{AVALIAÇÃO QUÍMICA}

Os mesmos dois peixes utilizados para as avaliações microbiológicas foram posteriormente preparados para as análises químicas. Retirou-se a pele de cada peixe e cortou-se o músculo do filé em pedaços menores que $1 \mathrm{~cm}^{3}$. Em tubo de polipropileno cônico de $50 \mathrm{~mL}$ foram pesados $5,0 \mathrm{~g}$ do músculo, adicionaram-se $30 \mathrm{~mL}$ de ácido tricloroacético (TCA) (Sigma) $5 \%$ e efetuouse a homogeneização em extrator (Ultra-Turrax marca IKA) por 1 minuto. O conteúdo do tubo permaneceu em repouso por 30 minutos para que houvesse a precipitação das proteínas. Filtrou-se o precipitado em papel filtro e adicionou-se TCA $5 \%$ até completar o volume do balão volumétrico $(50 \mathrm{~mL})$. Manteve-se o extrato desproteinizado sob refrigeração até o momento das análises.

Para determinação de bases nitrogenadas voláteis (BNV) seguiu-se o método de Howgate (2009). Alíquotas de $20 \mathrm{~mL}$ do extrato desproteinizado foram destiladas em destilador tipo Kjeldhal (marca Marconi). A amônia liberada foi coletada em solução de ácido bórico (Sigma) com indicadores e quantificada por titulometria com ácido clorídrico padronizado. Analisou-se a concentração de trimetilamina (TMA) colorimetricamente como picrato de TMA pelo método de Dyer (1945), modificado por Murray e Gibson (1972). Determinou-se o triptofano livre pelo método descrito por Contreras e Lapa Guimarães (1989), mediante reação com antrona em meio ácido na presença de íons de $\mathrm{Fe}^{+2}$ e $\mathrm{Fe}^{+3}$. O complexo colorido formado absorve fortemente a $545 \mathrm{~nm}$, sendo estável por várias horas.

\subsection{ANÁLISE ESTATÍSTICA}

A correlação entre os diversos parâmetros determinados em pescada amarela foi avaliada por Análise de Componentes Principais (ACP), utilizando-se os programas Excel 7 (MICROSOFT, 2007) e Statistica 9 (STATSOFT, 2010).

\section{RESULTADOS E DISCUSSÃO}

\subsection{AVALIAÇÃO SENSORIAL (MIQ)}

Após a captura e morte dos peixes iniciam-se as alterações nas características sensoriais 
da pescada amarela que se acentuam ao longo do armazenamento. Segundo Santos et al. (2014), essas alterações podem ser notadas pela perda da coloração amarelada; desaparecimento do brilho, modificação na transparência das córneas e delineamento das pupilas; alteração da coloração, odor e viscosidade do muco presente nas brânquias; perda da rigidez do músculo e fragilidade da membrana peritoneal, entre outras. A quantificação dessas alterações pelo protocolo MIQ permite estimar o tempo de armazenamento dos peixes em gelo.

As amostras de pescada amarela obtidas de pescadores artesanais e avaliadas 1 e 2 dias após a captura apresentaram IQ de 0,2 e 1,29, respectivamente. Utilizando os valores de IQ obtidos na avaliação sensorial dos peixes e a curva de calibração (SANTOS 2011) durante o armazenamento da pescada amarela em gelo determinaram-se períodos de 0,5 e 1,3 dias após a captura, valores que correspondem ao tempo conhecido de captura desses peixes. Para as amostras de pescada amarela adquiridas em pontos de comercialização foram determinados IQ variando de 2 a 23, com médias de 3,60 a 19,66. Utilizando a curva de calibração MIQ foi possível estimar o tempo após captura que cada amostra de pescada amarela apresentava e assim conhecer o seu grau de frescor. O tempo provável após a captura desses exemplares de pescada amarela variou de 3 a 14 dias, como mostra a Tabela 1.

\section{TABELA 1 - RESULTADOS DE IQ DETERMINADOS NAS ANÁLISES SENSORIAIS DAS PESCADAS AMARELAS ADQUIRIDAS EM PONTOS DE COMERCIALIZAÇÃO DAS CIDADES DE SANTOS, SÃO VICENTE E PRAIA GRANDE}

\begin{tabular}{|c|c|c|c|c|}
\hline Cidade & $\begin{array}{c}\text { Pontos de } \\
\text { comercialização }\end{array}$ & Tipo de comércio & Média IQ & $\begin{array}{l}\text { Dias após } \\
\text { captura* }^{*}\end{array}$ \\
\hline \multirow{6}{*}{ Santos } & $A$ & Ambulante & 10,83 & 8 \\
\hline & $B$ & Ambulante & 12,66 & 9 \\
\hline & $\mathrm{C}$ & Ambulante & 11,83 & 9 \\
\hline & $\mathrm{D}$ & Peixaria & 16,00 & 12 \\
\hline & E & Peixaria & 13,14 & 10 \\
\hline & $\mathrm{F}$ & Peixaria & 3,60 & 3 \\
\hline \multirow{5}{*}{ Praia Grande } & G & Peixaria & 12,48 & 9 \\
\hline & $\mathrm{H}$ & Peixaria & 11,57 & 9 \\
\hline & I & Peixaria & 13,66 & 10 \\
\hline & $J$ & Peixaria & 9,00 & 7 \\
\hline & K & Peixaria & 8,50 & 6 \\
\hline \multirow{3}{*}{ São Vicente } & L & Peixaria & 17,00 & 13 \\
\hline & M & Peixaria & 19,66 & 14 \\
\hline & $\mathrm{N}$ & Peixaria & 9,80 & 7 \\
\hline
\end{tabular}

*Estimativa baseada na curva de calibração do MIQ previamente desenvolvido. 
Segundo Santos (2011), a pescada amarela parcialmente eviscerada com IQ entre 0 a 3 encontra-se em elevado estado de frescor ( 0 a 3 dias de armazenamento em gelo). IQ de 5 a 13 indicam de 5 a 10 dias de armazenamento em gelo, enquanto que IQ superiores a 19 são característicos de peixes com mais de 14 dias de armazenamento. Além disso, no mesmo estudo foi verificado que a pescada amarela eviscerada resfriada em gelo apresenta vida útil de aproximadamente 8 dias, pois após esse período passa a evidenciar características sensoriais que a tornam indesejável para consumo e contagens de micro-organismos psicrotróficos acima de 7 Log UFC/g. Considerando-se esse limite, 9 dos 14 pontos de comercialização avaliados forneceram pescada amarela resfriada com tempos de armazenamento superiores ao adequado para consumo.

A vida útil de peixes armazenados em gelo, de acordo com Contreras (2002), pode variar de 4 a 20 dias dependendo, principalmente, da espécie, mas também sofre influência do método de captura e da manipulação. A maioria das espécies de peixes apresenta vida útil entre 1 e 2 semanas, porém as de tamanho pequeno e particularmente aquelas sem escamas ou com escamas pequenas tem vida útil ainda menor. Espécies de pescada duram cerca de 8 dias (CONTRERAS, 2002), enquanto o peixe sapo (Lophius gastrophysus) tem vida útil em gelo de apenas 2 dias (ABREU et al., 2008). Já a corvina (Micropogonias furnieri) eviscerada e estocada à temperatura de $0{ }^{\circ} \mathrm{C}$ pode ser consumida com pouco risco para a saúde até o décimo quarto dia (TEIXEIRA et al., 2009).

\subsection{AVALIAÇÃO MICROBIOLÓGICA}

As amostras de pescada amarela obtidas de pescadores artesanais (1 e 2 dias após a captura) estavam livres de Salmonella, E. coli e Staphylococcus coagulase positiva (Tabela 2).

\section{TABELA 2 - CONTAGENS DE MICRO-ORGANISMOS PSICROTRÓFICOS E COLIFORMES TOTAIS, VALORES DE BASES NITROGENADAS VOLÁTEIS (BNV), TRIMETILAMINA (TMA) E TRIPTOFANO LIVRE EM PESCADA AMARELA ADQUIRIDA DE PESCADOR ARTESANAL}

\begin{tabular}{cccccc}
\hline $\begin{array}{c}\text { Pescada } \\
\text { amarela }\end{array}$ & $\begin{array}{c}\text { Psicrotróficos } \\
\text { (Log UFC/g) }\end{array}$ & $\begin{array}{c}\text { Coliformes } \\
\text { totais } \\
\text { (Log UFC/g) }\end{array}$ & $\begin{array}{c}\text { BNV } \\
\text { (mg/100 g) }\end{array}$ & $\begin{array}{c}\text { TMA } \\
\text { (mg/100 g) }\end{array}$ & $\begin{array}{c}\text { Triptofano } \\
\text { livre } \\
\text { (mg/100 g) }\end{array}$ \\
\hline 1 dia após captura & 4,48 & 3,58 & 25,26 & 0,80 & 2,31 \\
\hline 2 dias após captura & 5,33 & 3,95 & 18,62 & 0,50 & 3,66 \\
\hline
\end{tabular}

Os resultados das análises microbiológicas dos peixes adquiridos em pontos de comercialização estão apresentados na Tabela 3. Em relação à Salmonella e E.coli, $100 \%$ dos peixes analisados estavam livres desses micro-organismos. Staphylococcus coagulase positiva foram encontrados em três $(10,7 \%)$ exemplares de pescada amarela com contagens próximas de 2 Log UFC/g, mas enquadrando-se no limite estipulado pela RDC n. 12 da ANVISA (BRASIL, 2001).

As contagens de micro-organismos psicrotróficos variaram de 4,77 a 9,95 Log UFC/g. Padrões internacionais (ICMSF, 1986) estabelecem 7 Log UFC/g como limite máximo aceitável para a contagem de bactérias aeróbias mesófilas e psicrotróficas na superfície muscular do pescado. Considerando esse limite, $50 \%$ dos peixes apresentaram contagens de psicrotróficos acima dos padrões internacionais admitidos como seguros para consumo. Coliformes totais estavam presentes em todas as amostras em contagens superiores a 2 Log UFC/g, sendo encontrados níveis de até 7 Log UFC/g em 1 das amostras. 
TABELA 3 - RESULTADOS DAS ANÁLISES MICROBIOLÓGICAS REALIZADAS NAS PESCADAS AMARELAS ADQUIRIDAS EM PONTOS DE COMERCIALIZAÇÃO DAS CIDADES DE SANTOS, SÃO VICENTE E PRAIA GRANDE

\begin{tabular}{|c|c|c|c|c|c|c|c|}
\hline Cidade & $\begin{array}{l}\text { Ponto } \\
\text { de } \\
\text { venda }\end{array}$ & Peixe & $\begin{array}{c}\text { Salmonella } \\
s p .^{a}\end{array}$ & $\begin{array}{c}\text { S. } \\
\text { aureus }^{b}\end{array}$ & Psicrotróficos $^{b}$ & Coliformes $^{b}$ & E.colib \\
\hline \multirow{12}{*}{ Santos } & \multirow{2}{*}{ A } & 1 & - & $<1$ & 6,95 & $<2$ & $<1$ \\
\hline & & 2 & - & $<1$ & 6,60 & $<2$ & $<1$ \\
\hline & \multirow{2}{*}{ B } & 1 & - & $<1$ & 7,02 & $<2$ & $<1$ \\
\hline & & 2 & - & $<1$ & 6,78 & $<2$ & $<1$ \\
\hline & \multirow{2}{*}{ C } & 1 & - & 2 & 6,70 & $<2$ & $<1$ \\
\hline & & 2 & - & $<1$ & 6,84 & $<2$ & $<1$ \\
\hline & \multirow{2}{*}{ D } & 1 & - & $<1$ & 8,00 & 5,60 & $<1$ \\
\hline & & 2 & - & $<1$ & 9,00 & 6,30 & $<1$ \\
\hline & \multirow{2}{*}{ E } & 1 & - & $<1$ & 9,95 & 5,00 & $<1$ \\
\hline & & 2 & - & 2 & 9,48 & $<5$ & $<1$ \\
\hline & \multirow{2}{*}{$\mathrm{F}$} & 1 & - & $<1$ & 4,78 & 3,30 & $<1$ \\
\hline & & 2 & - & $<1$ & 5,78 & 3,83 & $<1$ \\
\hline \multirow{10}{*}{$\begin{array}{l}\text { Praia } \\
\text { Grande }\end{array}$} & \multirow{2}{*}{ G } & 1 & - & $<1$ & 8,70 & 5,60 & $<1$ \\
\hline & & 2 & - & $<1$ & 8,78 & 5,48 & $<1$ \\
\hline & \multirow{2}{*}{$\mathrm{H}$} & 1 & - & 3 & 8,78 & 6,70 & $<1$ \\
\hline & & 2 & - & $<1$ & 8,48 & 7,11 & $<1$ \\
\hline & \multirow{2}{*}{1} & 1 & - & $<1$ & 7,78 & 5,00 & $<1$ \\
\hline & & 2 & - & $<1$ & 8,84 & 4,84 & $<1$ \\
\hline & \multirow{2}{*}{$\mathrm{J}$} & 1 & - & $<1$ & 8,30 & $<5$ & $<1$ \\
\hline & & 2 & - & $<1$ & 7,84 & 4,00 & $<1$ \\
\hline & \multirow{2}{*}{$\mathrm{K}$} & 1 & - & $<1$ & 7,20 & 4,84 & $<1$ \\
\hline & & 2 & - & $<1$ & 7,36 & 5,00 & $<1$ \\
\hline \multirow{6}{*}{$\begin{array}{c}\text { São } \\
\text { Vicente }\end{array}$} & \multirow{2}{*}{ L } & 1 & - & $<1$ & 9,95 & 4,84 & $<1$ \\
\hline & & 2 & - & $<1$ & 9,00 & 4,78 & $<1$ \\
\hline & \multirow{2}{*}{ M } & 1 & - & $<1$ & 8,90 & 5,00 & $<1$ \\
\hline & & 2 & - & $<1$ & 8,78 & 4,90 & $<1$ \\
\hline & \multirow{2}{*}{$\mathrm{N}$} & 1 & - & $<1$ & 7,00 & 4,00 & $<1$ \\
\hline & & 2 & - & $<1$ & 6,30 & 4,48 & $<1$ \\
\hline
\end{tabular}

$\mathrm{a}=$ ausência; - = presença + em $25 \mathrm{~g}$. $b=\log$ UFC/g. 
Os resultados obtidos são semelhantes aos encontrados por Moura (2007), que avaliou a qualidade de peixes marinhos procedentes de feira livre em Fortaleza (CE) e verificou ausência de Samonella sp. em $100 \%$ das amostras. No mesmo estudo 8,33\% das amostras analisadas foram positivas para Staphylococcus coagulase positiva, embora não tenham ultrapassado o limite de tolerância para amostra indicativa (3 Log UFC/g) (BRASIL, 2001). Níveis mais altos de contaminação foram observados por Alvares et al. (2008), que analisaram 88 amostras de pescada e atum provenientes de três tipos de estabelecimentos comerciais (feira-livre, supermercados e CEAGESP) da Grande São Paulo. Entre as 79,6 \% amostras contaminadas por coliformes fecais, 50 \% ultrapassou o limite da legislação. Silva, Matté e Matté (2008) avaliaram a qualidade microbiológica de 20 amostras de peixes comercializados em feiras livres, sendo 9 de salmão, 8 de atum, 1 de badejo e 2 de sashimi. Encontraram coliformes termotolerantes em valores superiores a 2 Log NMP/g em 5 amostras e Escherichia coli foi isolada em 1 amostra (totalizando 6 amostras impróprias para o consumo). Staphylococcus aureus foi detectado, porém com valores abaixo dos limites de tolerância estabelecidos pela ANVISA (BRASIL, 2001). Andrade (2006), avaliando o prazo de vida comercial do atum com pele (Thunnus atlanticus) armazenado sob refrigeração, encontrou valores médios nas contagens de bactérias heterotróficas aeróbias psicrotróficas variando de 9 a 17 Log UFC/g nos primeiros 6 dias de armazenamento.

De acordo com os resultados do presente estudo, todos os exemplares analisados apresentaram-se próprios para consumo em relação à qualidade microbiológica exigida pela legislação brasileira em vigor (BRASIL, 2001). No entanto, $50 \%$ dos exemplares analisados não estavam de acordo com os padrões internacionais (ICMSF, 1986) em relação aos níveis de psicrotróficos encontrados. A baixa incidência e ausência de micro-organismos patogênicos nesses exemplares sugere sua boa qualidade microbiológica. Tais bactérias não fazem parte da microbiota e do habitat do pescado e quando presentes indicam contaminação por animais de sangue quente (HUSS, 1997).

\subsection{AVALIAÇÃO QUÍMICA}

As amostras de pescada amarela obtidas de pescadores artesanais apresentaram valores de BNV e TMA inferiores aos limites estabelecidos pela legislação brasileira (BRASIL, 1997), encontrando-se adequadas para o consumo (Tabela 2). Os valores de BNV e TMA determinados nos peixes 1 dia após a captura foram mais elevados que os detectados nos peixes avaliados 2 dias após a captura. Tais resultados demonstram como a produção desses compostos varia, dificultando sua utilização como índices de frescor confiáveis.

Os valores de triptofano livre detectados foram de 2,31 e 3,66 mg/100 g em amostras de pescada amarela avaliadas 1 e 2 dias após a captura, respectivamente. Considerando o elevado estado de frescor desses peixes, apenas valores de triptofano bastante elevados seriam indicativos de proteólise.

Nas amostras de pescada amarela adquiridas em pontos de comercialização (Tabela 4) foram determinados valores de TMA desde $0,04 \mathrm{mg} / 100 \mathrm{~g}$ até $28,90 \mathrm{mg} / 100 \mathrm{~g}$, ultrapassando sete vezes o valor tolerado pela legislação (BRASIL, 1997). Os valores de BNV variaram de 14,0 mg/100 g (também inferior ao encontrado nos peixes com tempo de captura conhecido) a $89,6 \mathrm{mg} / 100 \mathrm{~g}$ (valor três vezes mais elevado que o permitido pela legislação brasileira).

Os teores de TMA constatados estavam acima do permitido pela legislação em $50 \%$ dos exemplares de pescada amarela adquiridos no varejo e $65 \%$ das amostras estariam impróprias para consumo em relação à concentração de BNV. Teores de TMA superiores a $4 \mathrm{mg} / 100 \mathrm{~g}$ nem sempre 
são indicativos de amostras impróprias para consumo, pois tais níveis de TMA foram detectados em amostras com baixa concentração de BNV (Tabela 4) e baixo IQ (Tabela 1).

No Mercado Comum Europeu, as diretivas 95/149/EEC e 91/493/EEC estabelecem os valores de $35 \mathrm{mg}$ de BNV e $12 \mathrm{mg}$ de TMA/100 g de peixe fresco como limites de aceitação (RUIZ-CAPILLAS \& MORAL, 2001). Tais valores são superiores ao recomendado pela legislação brasileira, principalmente para TMA. Amostras que apresentam altos valores de TMA em relação aos valores de BNV podem conter numerosos micro-organismos produtores de TMA e, nesse caso, esse composto predomina na composição das BNV.

As análises de triptofano resultaram em valores variando desde $0,18 \mathrm{mg} / 100 \mathrm{~g}$ até $14,09 \mathrm{mg} / 100 \mathrm{~g}$. Em 9 das 12 amostras que apresentaram teores de triptofano livre superiores a $5 \mathrm{mg} / 100 \mathrm{~g}$, os valores de BNV também foram superiores ao limite de $30 \mathrm{mg} / 100 \mathrm{~g}$ estabelecido pela legislação. No entanto, teores elevados de triptofano livre também foram detectados em amostras com baixo conteúdo de BNV. Tal fato, exemplifica a dificuldade para correlacionar esse parâmetro químico e a qualidade dos peixes adquiridos no comércio.

Foram encontrados valores muito heterogêneos em peixes adquiridos no mesmo ponto de comercialização, principalmente entre as amostras dos pontos A, G e H em relação aos teores de TMA e pontos J, L e M em relação aos teores de BNV. Nessas amostras também foram observadas cargas de psicrotróficos superiores a $6 \mathrm{Log} \mathrm{UFC} / \mathrm{g}$, exceto para o ponto de comercialização A, e valores de IQ superiores a 10, exceto para o ponto de comercialização J. Por outro lado, nas amostras $\mathrm{F}$ e N com menores valores de TMA, BNV e de triptofano livre e maior homogeneidade entre os resultados, notou-se também menor contaminação microbiológica e valores baixos de IQ.

Os resultados obtidos indicam que em amostras muito frescas ( $<3$ dias de armazenamento em gelo), a boa qualidade microbiológica está aliada à alta qualidade sensorial e baixa concentração de compostos químicos relacionados à atividade bacteriana e enzimática. No entanto, quando determinada população bacteriana passa a se desenvolver, a velocidade de produção de subprodutos da sua atividade e as alterações sensoriais decorrentes podem ser muito variáveis em peixes do mesmo lote.

\subsection{ANÁLISE DE COMPONENTES PRINCIPAIS (ACP)}

Na ACP aplicada aos resultados obtidos com amostras de pescada amarela, os três primeiros componentes principais (CP 1, CP 2 e CP 3) representaram 37,50\%, 26,03\% e $16,32 \%$ da variação entre as amostras, totalizando $79,85 \%$. A ACP confirmou informações importantes sobre as características das amostras de pescada amarela adquiridas nos diversos pontos de comercialização.

$\mathrm{Na}$ Figura 1a, que apresenta os quadrantes definidos pelos CP 1 e CP 2, verifica-se que as amostras dos pontos de comercialização F, N, K são as mais homogêneas (pontos com localização próxima no gráfico) e apresentam baixos valores de BNV e IQ, já que se encontram nos quadrantes opostos a esses atributos. As amostras dos pontos de comercialização D, E, L, M apresentaram os maiores valores de IQ, psicrotróficos, BNV, TMA e triptofano livre. A Figura $1 \mathrm{~b}$, que apresenta os quadrantes definidos pelos CP 1 e CP 3 , confirma que as amostras dos pontos $B$ e $E$, e uma amostra dos pontos A, D, G e I com valores de BNV acima de $60 \mathrm{mg} / 100 \mathrm{~g}$ localizaram-se mais próximas do vetor BNV.

Simat et al. (2012) utilizaram a ACP para analisar as relações entre os parâmetros de qualidade avaliados em peixes das espécies Sparus aurata criados e selvagens e duas populações diferentes do peixe Boops boops. Encontraram alta correlação entre as variáveis BNV, TMA e IQ e afirmaram que a ACP foi útil para distinguir os peixes selvagens em relação aos grupos de peixes provenientes ou relacionados a sistemas de criação. 
TABELA 4 - RESULTADOS DAS ANÁLISES QUÍMICAS REALIZADAS NAS PESCADAS AMARELAS ADQUIRIDAS EM PONTOS DE COMERCIALIZAÇÃO

\begin{tabular}{|c|c|c|c|c|c|}
\hline Cidade & $\begin{array}{l}\text { Ponto de } \\
\text { venda }\end{array}$ & Peixe & $\begin{array}{c}\text { TMA } \\
(\mathrm{mg} / 100 \mathrm{~g})\end{array}$ & $\begin{array}{c}\text { BNV } \\
(\mathrm{mg} / 100 \mathrm{~g})\end{array}$ & $\begin{array}{l}\text { Triptofano } \\
(\mathrm{mg} / 100 \mathrm{~g})\end{array}$ \\
\hline \multirow{12}{*}{ Santos } & \multirow{2}{*}{ A } & 1 & 0,25 & 60,99 & 2,60 \\
\hline & & 2 & 13,44 & 46,08 & 3,77 \\
\hline & \multirow[b]{2}{*}{ B } & 1 & 3,39 & 89,55 & 5,72 \\
\hline & & 2 & 0,67 & 73,39 & 2,09 \\
\hline & \multirow{2}{*}{ C } & 1 & 28,93 & 35,00 & 0,66 \\
\hline & & 2 & 5,40 & 36,02 & 0,66 \\
\hline & \multirow{2}{*}{ D } & 1 & 0,51 & 75,74 & 12,57 \\
\hline & & 2 & 0,04 & 47,61 & 11,75 \\
\hline & \multirow{2}{*}{ E } & 1 & 17,01 & 70,00 & 2,46 \\
\hline & & 2 & 15,26 & 71,99 & 1,39 \\
\hline & \multirow{2}{*}{$\mathrm{F}$} & 1 & 0,50 & 14,00 & 0,20 \\
\hline & & 2 & 0,15 & 14,34 & 1,97 \\
\hline \multirow{10}{*}{$\begin{array}{l}\text { Praia } \\
\text { Grande }\end{array}$} & \multirow{2}{*}{ G } & 1 & 11,11 & 52,64 & 0,41 \\
\hline & & 2 & 0,29 & 68,65 & 5,61 \\
\hline & \multirow{2}{*}{$\mathrm{H}$} & 1 & 0,26 & 29,52 & 7,03 \\
\hline & & 2 & 18,15 & 41,02 & 9,47 \\
\hline & \multirow{2}{*}{1} & 1 & 4,68 & 71,78 & 6,73 \\
\hline & & 2 & 4,66 & 35,60 & 14,09 \\
\hline & \multirow{2}{*}{ J } & 1 & 0,88 & 35,29 & 4,79 \\
\hline & & 2 & 0,36 & 22,49 & 12,05 \\
\hline & \multirow{2}{*}{ K } & 1 & 15,02 & 23,71 & 1,20 \\
\hline & & 2 & 13,34 & 21,42 & 0,18 \\
\hline \multirow{6}{*}{ São Vicente } & \multirow{2}{*}{ L } & 1 & 14,34 & 53,57 & 10,43 \\
\hline & & 2 & 13,84 & 27,00 & 14,08 \\
\hline & \multirow{2}{*}{ M } & 1 & 1,26 & 26,35 & 0,19 \\
\hline & & 2 & 0,14 & 36,99 & 6,79 \\
\hline & \multirow{2}{*}{$\mathrm{N}$} & 1 & 3,46 & 21,92 & 1,68 \\
\hline & & 2 & 6,40 & 14,16 & 2,20 \\
\hline
\end{tabular}



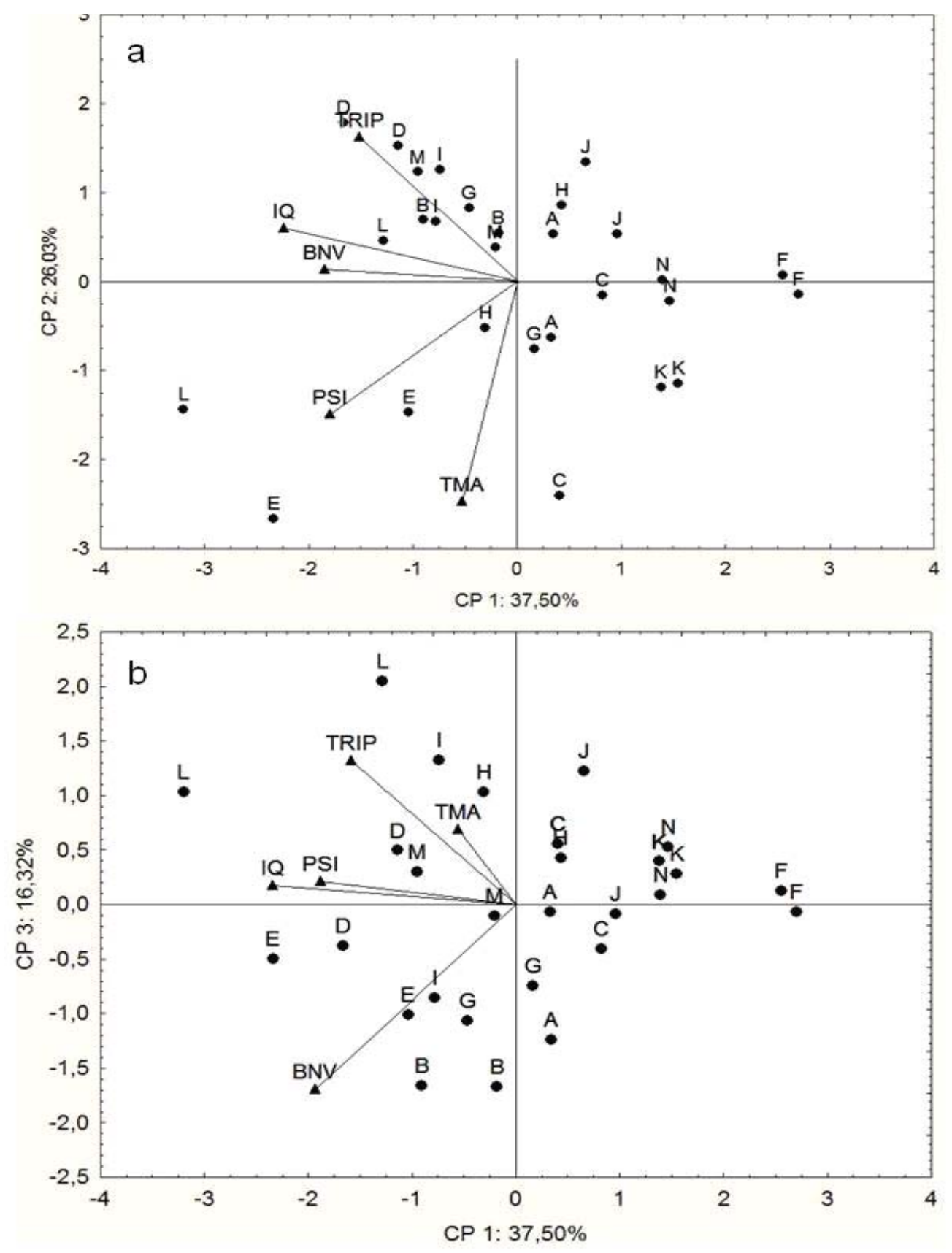

\section{FIGURA 1 - ANÁLISE DE COMPONENTES PRINCIPAIS REALIZADA COM OS RESULTADOS DOS PARÂMETROS AVALIADOS EM PESCADAS AMARELAS (Cynoscion acoupa) ADQUIRIDAS NO COMÉRCIO DE SANTOS, SÃO VICENTE E PRAIA GRANDE}

$a=$ visualização de parâmetros e amostras alocados no plano CP 1 e CP 2; b = visualização de parâmetros e amostras alocados no plano CP 1 e CP 3.

\section{CONCLUSÃo}

O protocolo MIQ foi efetivo na avaliação sensorial das amostras de pescada amarela (C. acoupa) resfriadas. Em 11 dos 14 pontos de comercialização pesquisados, os peixes tinham mais de 1 semana após captura e evidenciaram características sensoriais inadequadas para consumo. 
As amostras apresentaram-se próprias para consumo em relação aos limites estabelecidos pela legislação brasileira para Salmonella sp., Staphylococcus coagulase positiva e E.coli. No entanto, as altas contagens de psicrotróficos e coliformes totais encontrados em mais de $50 \%$ das amostras indicam risco de contaminação por micro-organismos nocivos à saúde, uma vez que os locais pesquisados não estão, ainda, em conformidade com as boas práticas de manipulação e conservação do pescado. Em relação aos compostos químicos avaliados verificou-se grande variabilidade dos teores de BNV, TMA e triptofano livre em peixes de mesma procedência e que pelo menos $50 \%$ das pescadas amarelas resfriadas estava em condições inadequadas para o consumo quanto aos limites químicos impostos pela legislação brasileira. Os resultados alertam sobre o baixo grau de frescor em que normalmente essa espécie de elevado valor comercial e uma das mais capturadas no litoral brasileiro é oferecida ao consumidor. Esforços devem ser efetuados com o objetivo de aprimorar o conhecimento dos consumidores sobre a qualidade do pescado e educar os comerciantes e manipuladores sobre o manuseio e o armazenamento adequados de peixes in natura a fim de preservar ao máximo sua qualidade.

\section{ABSTRACT \\ QUALITY ASSESSMENT OF COMMERCIALLY CHILLED WEAKFISH (Cynoccion acoupa) USING THE QUALITY INDEX METHOD (QIM) AND CHEMICAL AND MICROBIAL ANALYSES}

The quality of chilled Acoupa weakfish (Cynoscion acoupa) marketed in fourteen retail markets in the cities of Santos, São Vicente and Praia Grande (São Paulo, Brazil) was evaluated using chemical and microbial analyses. The Quality Index Method (QIM) was employed to provide sensory analysis of freshness. Samples of fresh Acoupa weakfish obtained from small-scale fishermen on the day of capture were used as control. The samples of Acoupa weakfish that were obtained from commercial markets showed quality indices (QI) ranging from 2 to 23 , suggesting a storage time of between 3 to 14 days, respectively. All the fish that were analyzed were free from Salmonella sp. and Escherichia coli. The Staphylococcus aureus counts were lower than the amount allowed by Brazilian legislation. Psychrotrophic bacteria counts higher than 7 Log CFU/g were observed in $50 \%$ of the fish. The total coliform counts ranged from 2 Log CFU/g to $7 \mathrm{Log}$ CFU/g. The TMA and VBN contents were higher than the amount allowed by Brazilian legislation in $50 \%$ and $65 \%$ of the fish, respectively. The results showed that a large amount of the chilled Acoupa weakfish commercialized in retail markets presented low levels of freshness and pointed to the need to train retailers and employees about good practices in the processing and storage of fresh fish in order to maintain quality.

KEY-WORDS: FRESHNESS; FISH; QIM; SENSORY EVALUATION.

\section{REFERÊNCIAS}

1 ABREU, M.G.; FREITAS, M.Q.; JESUS, E.F.O.; SÃO CLEMENTE, S.C.; FRANCO, R.M.; BORGES, A. Caracterização sensorial e análise bacteriológica do peixe-sapo (Lophius gastrophysus) refrigerado e irradiado. Ciência Rural, v.38, n.2, p.498-503, 2008.

2 ÁLVARES, P.P. et al. Análise das características higiênico-sanitárias e microbiológicas de pescado comercializado na grande São Paulo. Higiene Alimentar, v.22, n.161, p.88-93, 2008.

3 ANDRADE, P.F. Avaliação do prazo de vida comercial do atum (Thunnus atlanticus) armazenado sob refrigeração. 2006. 97 f. Dissertação (Mestrado em Higiene Veterinária e Processamento Tecnológico de Produtos de Origem Animal) - Faculdade de Veterinária, Universidade Federal Fluminense, Niterói, 2006.

4 ANDRADE, S.C.S.; MÁRSICO, E.T.; FRANCO, R.M.; GODOY, R.L.O.; PACHECO, S.; QUEIROZ, M.F.; GUIMARÃES, C.F.M. Validade comercial de sardinhas inteiras e refrigeradas avaliada por análises físico-químicas, bacteriológicas e sensorial. Ciência Rural, v.42, n.10, p.1901-1907, 2012.

5 Association of Official Analytical Chemistry (AOAC). Official methods of analysis of AOAC International. $18^{\text {th }}$ ed. Gaithersburg, 2007. v.1

6 BRASIL. Agência Nacional de Vigilância Sanitária. RDC n.12, 02 de janeiro de 2001. Aprova o regulamento técnico sobre padrões microbiológicos para alimentos. Diário Oficial [da] República Federativa do Brasil, Brasília, 10 jan. 2001. Seção 1, p.45-47.

7 BRASIL. Ministério da Agricultura, Pecuária e Abastecimento. Portaria $n^{\circ}$ 185, de 13 de maio de 1997. Regulamento técnico de identidade e qualidade de peixe fresco (inteiro e eviscerado). Diário Oficial [da] República Federativa do 
Brasil, Brasília, 19 maio, 1997. Seção 1, p.10282.

8 BRASIL. Ministério da Pesca e Aquicultura (MPA). Boletim estatístico da pesca e aquicultura 2008-2009, 2010. Disponível em: http://www.mpa.gov.br/mpa/seap/Jonathan/mpa3/docs/anu\%E1rio\%20da\%20pesca\%20completo2.pdf. Acesso em: 15/10/2011.

9 BRASIL. Ministério da Pesca e Aquicultura (MPA). Boletim estatístico da pesca e aquicultura, 2010. Disponível em: http://www.mpa.gov.br/images/Docs/Informacoes $\% 20$ e 20 Estatisticas/Boletim $\% 20$ Estat $\%$ C3\%ADstico\%20MPA\%20 2010.pdf. Acesso em: 26/03/2012a.

10 BRASIL. Ministério da Pesca e Aquicultura (MPA). Boletim estatístico da pesca e aquicultura, 2011, 2012b. Disponível em: http://www.mpa.gov.br/index.php/monitoramento-e-controle/informacoes-e-estatisticas. Acesso em: 26/08/2013.

11 BREMNER, H. A. A convenient easy to use system for estimating the quality of chilled seafood. Fish Processing Bulletin, v.7, p.59-70, 1985 .

12 CONTRERAS, E.S.G. Bioquímica de pescados e invertebrados. Santiago de Chile: Centro de Estúdios em Ciência y Tecnologia de Alimentos, 2002. 309 p.

13 CONTRERAS, E.S.G.; LAPA GUIMARÃES, J.G. Determinação rápida de triptofano por reação com antrona. CONGRESSO BRASILEIRO DE CIÊNCIA E TECNOLOGIA DE ALIMENTOS, 12.,1989, Rio de Janeiro. Anais... Rio de Janeiro: SBCTA, 1989. p.152.

14 DYER, W.J. Amines in fish muscle. 1. Colorimetric determination of TMA as picrat salt. Journal of the Fisheries Research Board Canada, v.6, p.351-358, 1945.

15 HOWGATE, P. Tradicional methods. In: REHBEIN, H.; OEHLENSCHLÄGER, J. (Eds.). Fishery products: quality, safety and authenticity. Chichester, UK: John Wiley and Sons, 2009. Chap. 2, p. 19-41.

16 HUSS, H.H. Garantia da qualidade dos produtos da pesca. Roma: FAO, 1997. 176 p. (FAO - Documento Técnico sobre a Pesca, 334).

17 HYDILG, G.; NIELSEN, J. A rapid method for quality management. In: FINAL MEETING OF THE CONCERTED ACTION - EVALUATION OF FISH FRESHNESS,1997, Nantes. Anais... Paris: International Institute of Refrigeration, 1997. p. 297-305.

18 International Commission on Microbiological Specifications for Foods (ICMSF). Microorganisms in foods. 2. Sampling for microbiological analysis: principles and specific applications. Buffalo: University of Toronto, 1986.

19 JOHNSTON, R.W.; TOMPKIN, R.B. Meat and poultry products. In: VANDERZANT, C.; SPLITTSTOESSER, D.F. (eds.) Compendium of methods for the microbiological examination of foods. Washington: APHA, 1992. Chap.44, p.821835.

20 LAPA-GUIMARÃES, J.; FELÍCIO, P.E.; CONTRERAS, E.S.G. Chemical and microbial analyses of squid muscle (Loligo plei) during storage in ice. Food Chemistry, v.91, n.3, p.477-483, 2005.

21 LAPA-GUIMARÃES, J.; FELÍCIO, P.E.; CONTRERAS, E.S.G. An alternative approach for improving freshness indices for squid (Loligo plei). Acta Alimentaria, v.42, n.3, p.437-450, 2013.

22 KUSHIDA, M.M. Validação de métodos laboratoriais: avaliação do sistema BAX de análise de Salmonella sp. em alimentos por reação de Polimerase em cadeia (PCR). 2005. 194 f. Tese (Doutorado em Ciência de Alimentos) Faculdade de Engenharia de Alimentos, Universidade Estadual de Campinas, Campinas, 2005.

23 MAZORRA-MANZANO, M. A. Post mortem changes in black skipjack muscle during storage in ice. Food Chemistry and Toxicology, v.65, n.5, p.774-779, 2000.

24 MICROSOFT CORPORATION. Microsoft office excel 7 [programa de computador]. Redmond, Washington, 2007.

25 MOURA, H.F. A Qualidade dos alimentos no contexto da política de segurança alimentar: estudo de caso numa feira livre tradicional de Fortaleza. 2007. 116 f. Dissertação (Mestrado Profissional em Planejamento e Políticas Públicas) - Centro de Estudos Sociais Aplicados, Universidade Estadual do Ceará, Fortaleza, 2007.

26 MURRAY, C.K.; GIBSON, D.M. An investigation of the method of determining trimethylamine in fish muscle extracts by the formation of its picrate salt. Part I. Journal of Food and Technology, v.7, n.1, p.35-46, 1972.

27 NISSUI PHARMACEUTICAL CO. Market of food inspection. Japan, Fuji Keizai, 2009. Section 16, p. 2.

28 OLIVEIRA, V. M. Estudo da qualidade do camarão branco do Pacífico (Litopenaeus vannamei), inteiro e descabeçado estocado em gelo. 2005. 90 f. Tese (Doutorado em Higiene Veterinária e Processamento Tecnológico de Produtos de Origem Animal) - Faculdade de Veterinária, Universidade Federal Fluminense, Niterói, 2005.

29 RODRIGUES, T. P. Estudo de critérios para avaliação da qualidade da tilápia do Nilo (Oreochromis niloticus) cultivada, eviscerada e estocada em gelo. 2008. $116 \mathrm{f}$. Tese (Doutorado em Higiene Veterinária e Processamento Tecnológico de Produtos de Origem Animal) - Faculdade de Veterinária, Universidade Federal Fluminense, Niterói, 2008. 
30 ROMO, C.; ASTUDILLO, J.; MUÑOZ, O.; CONTRERAS Determinación de índices bioquímicos y funcionales relevantes para evaluar la conservación de jibia (Dosidicus gigas) a bordo. In: WORKSHOP ON FISH AND MOLLUSC LARVICULTURE, 1996, Santiago. Anais... Santiago: Universidad de Santiago de Chile, 1996. p. $197-213$.

31 RUIZ-CAPILLAS, C; MORAL, E. Correlation between biochemical and sensory quality indices in hake stored in ice. Food Research International, v.34, p.441-447, 2001.

32 SANTOS, A. P. B. Índices químicos, sensoriais e microbiológicos para avaliação do frescor de pescada amarela (Cynoscion acoupa) armazenada em gelo. 2011. 95 f. Dissertação (Mestrado em Ciências da Engenharia de Alimentos), Faculdade de Zootecnia e Engenharia de Alimentos, Universidade de São Paulo, Pirassununga, 2011.

33 SANTOS, A.P.B. ; KUSHIDA, M.M. ; VIEGAS, E.M.M.; LAPA-GUIMARÃES, J. Development of quality index method (QIM) scheme for acoupa weakfish (Cynoscion acoupa). LWT - Food Science and Technology, v.57, p.267-275, 2014.

34 SÃO PAULO. Secretaria de Agricultura e Abastecimento do Estado de São Paulo. Produção pesqueira marinha do estado de São Paulo no ano 2010. Informe. Instituto de Pesca - APTA - SAA - SP. Disponível em: http://www.pesca. sp.gov.br/estatistica/index.php. Acesso em: 24/10/2011.

35 SILVA, M.L; MATTÉ, G.R; MATTÉ, M.H. Aspectos sanitários da comercialização de pescado em feiras livres da cidade de São Paulo, SP/Brasil. Revista do Instituto Adolfo Lutz, v. 67, n. 3, p. 208-214, 2008.

36 ŠIMAT, V.; BOGDANOVIĆ, T.; KRŽELJ, M. Application of principal component analysis to characterize the effect of catching ground on post-mortem quality changes in ice stored sea bream (Sparus aurata, L.) and bogue (Boops boops, L.). Croatian Journal of Food Technology, Biotechnology and Nutrition, n.7, p.14-17, 2012.

37 STATSOFT INC. Statistica 9 for windows [programa de computador]. Tulsa, Oklahoma, 2010.

38 SVEINSDÓTTIR, K. et al. Application of quality index method (QIM) scheme in shelf life study of farmed Atlantic salmon (Salmo salar). Journal of Food Science, v.64, n.4, p.1570-1579, 2002.

39 TEIXEIRA, M.S.; BORGES, A.; FRANCO, R.M.; SÃO CLEMENTE, S.C.; FREITAS M.Q. Método de índice de qualidade (QIM): desenvolvimento de um protocolo sensorial para corvina (Micropogonias furnieri). Revista Brasileira de Ciência Veterinária, v. 6, n.2, p.83-88, 2009.

40 VAZ-PIRES, P.; SEIXAS, P. Development of new quality index method (QIM) schemes for cuttlefish (Sepia officinalis) and broadtail shortfin squid (IIlex coindetii). Food Control, v.17, p.942-949, 2006.

\section{AGRADECIMENTOS}

Este trabalho recebeu o apoio financeiro do Conselho Nacional de Desenvolvimento Científico e Tecnológico por meio de Auxílio à Pesquisa, processo 578423/2008-1, e bolsa de mestrado concedida pela Coordenação de Aperfeiçoamento de Pessoal de Nível Superior (CAPES) à aluna Ana Paula Billar dos Santos. 